\title{
Review: \\ Peningkatan Tata Kelola Wanamina di Wilayah Pesisir Kota Semarang: Peranan Praktis Struktur Vegetasi Mangrove
}

\section{The Improved Silvofishery's Management in Coastal Areas of Semarang City : Practical Roles Mangrove Vegetation Structure}

\author{
Endah Dwi Hastuti \\ Departemen Biologi, Fakultas Sains dan Matematika, Universitas Diponegoro \\ Jl. Prof. Soedarto, SH Tembalang, Semarang \\ Email : endah_pdil@yahoo.com
}

Diterima 13 April 2017 / Disetujui 25 Agustus 2017

\begin{abstract}
ABSTRAK
Penerapan wanamina di Indonesia telah berlangsung sejak lama, namun perkembangannya relatif lambat. Adanya konflik kepentingan hingga rendahnya partisipasi masyarakat merupakan kendala yang selalu ada dalam pengembangan wanamina. Meskipun perkembangan penerapan wanamina relatif lambat, namun manfaatnya telah mulai banyak dirasakan oleh masyarakat, mulai dari peningkatan produktivitas budidaya, manfaat hasil samping budidaya, biaya pengelolaan yang rendah hingga manfaat ekologis bagi perlindungan pantai dan daya dukungnya terhadap perikanan tangkap. Peningkatan kualitas lingkungan merupakan manfaat yang paling banyak dirasakan oleh pembudidaya. Sementara jasa-jasa lingkungan dari keberadaan ekosistem mangrove lebih banyak dirasakan oleh masyarakat sekitar khususnya nelayan karena semakin meningkatnya keragaman dan kelimpahan sumber daya ikan. Berbagai upaya pengembangan tata kelola telah dilakukan untuk meningkatkan produktivitas dan manfaat ekonomisnya serta mengurangi limbah dan biaya produksi dalam budidaya. Pengaturan jenis mangrove hingga pemanfaatan limbah pertanian dan peternakan merupakan strategi yang semakin banyak dipadukan dalam budidaya dengan sistem wanamina. Fungsi perlindungan dan ketahanannya dalam tambak wanamina juga semakin dipertimbangkan dalam pemilihan jenis mangrove yang akan ditanam. Peranan praktis dari jenis vegetasi mangrove menunjukkan adanya dampak yang signifikan dalam pengendalian kualitas lingkungan, penyediaan pakan alami hingga daya dukungnya terhadap sumber daya perikanan secara umum. Potensi pemanfaatan jangka panjang berupa produksi kayu mangrove juga menjadi faktor penting yang perlu dipertimbangkan untuk menghindari konflik pemanfaatan mangrove di masa yang akan datang. Pengelolaan ekosistem mangrove dan tambak secara terpadu diharapkan mampu menjembatani kepentingan pemerintah dalam melindungi wilayah pesisir, petambak dalam melakukan kegiatan budidaya serta nelayan penangkap ikan yang kesemuanya merupakan pemangku kepentingan yang tidak dapat diabaikan.
\end{abstract}

Kata kunci: budidaya, jasa lingkungan, mangrove, pengelolaan, wanamina

\begin{abstract}
The application of silvofishery system in Indonesia had been conducted since a long time ago, but the development is slow. The presence of conflict of interest to low community participation are the common problems in development of silvofishery application. Although the progress of silbofishery application is relatively slow, but its advantages are now obviously revealed, such as the improvement of aquaculture productivity, aquaculture by product, lower management cost, as well as ecological advantages in coastal protection and its carrying capacity to capture fisheries resources. Improvement of environment quality is the most valuable advantages for aquaculturists. In the meanwhile, environment services provided by mangrove ecosystem existence provide more advantages for local society especially for fishermen due to the improvement of fisheries resources diversity and abundance. Various efforts had been conducted to improve management development to enhance the productivity and economic benefit as well as to decrease effluent and production cost in aquaculture activities. Determination of mangrove species unto utilization of farm
\end{abstract}


waste and poultry manure had also been implemented in the integration of silvofishery aquaculture system. Protection role and sustainability of mangrove species within silvofishery pond had also been considered in the determination of mangrove plantation plan. Practical role of mangrove species showed the significant impact in environment quality control, preservation of natural feed as well as its carrying capacity on global fisheries resources. Long term utilization potential of mangrove such as timber also need to be considered to hinder future mangrove utilization conflict. Integrated management of mangrove ecosystem and fish ponds is expected to overcome the conflict of interest among government in protecting coastal area, aquaculturists in conducting aquacultre activities and fishermen in fish capturing activities whom are important stakeholders of coastal area.

Keywords: aquaculture, environment services, mangrove, management, silvofishery

\section{PENDAHULUAN}

Pengelolaan wilayah pesisir secara terpadu dengan mengkombinasikan kegiatan budidaya dengan upaya konservasi telah banyak berkembang di banyak negara. Upaya ini dianggap sebagai solusi dari kompetisi aspek ekonomi dan aspek ekologi. Upaya konservasi mangrove menjamin keberlanjutan ketersediaan dan pemanfaatan sumber daya wilayah pesisir, baik berupa sumber daya hayati maupun jasa-jasa lingkungan. Sehingga, upaya rehabilitasi mangrove semakin didorong pelaksanaannya baik di wilayah pesisir yang telah mengalami kerusakan maupun yang rentan terhadap kerusakan akibat penyusutan luas mangrove.

Kegiatan budidaya di masa lalu yang dilakukan dengan pengalihfungsian lahan mangrove menjadi lahan tambak telah menyisakan berbagai permasalahan bagi wilayah pesisir, baik secara ekologis maupun sosial ekonomi (Bush et al. 2010). Permasalahan yang ditimbulkan antara lain menurunnya sumber daya perikanan baik terhadap keragaman maupun kelimpahannya, meningkatnya pencemaran perairan, berkembangnya penyakit bagi kultivan, menurunnya tingkat pendapatan nelayan dan pembudidaya, hingga adanya konflik kepentingan pemanfaatan wilayah pesisir. Permasalahanpermasalahan tersebut mengakibatkan lahan-lahan bekas tambak di wilayah pesisir menjadi terbengkalai. Disisi lain, lahan bekas tambak yang tak terlindungi kian tergerus oleh pasang surut air laut sehingga mengalami abrasi.

Menurunnya luas mangrove di wilayah pesisir pantai disebabkan oleh adanya penebangan kayu mangrove disertai konversi hutan mangrove menjadi tambak ikan dan pemukiman (Bidayani et al. 2016a). Terjadinya konversi lahan tersebut didorong oleh asumsi masyarakat bahwa hutan mangrove memiliki nilai ekonomis yang lebih rendah dibandingkan dengan pertambakan. Hal tersebut menyebabkan peningkatan konversi hutan mangrove menjadi kawasan pertambakan, khususnya untuk pembudidayaan udang windu yang memiliki nilai ekonomis tinggi. Dampak yang ditimbulkan yaitu terjadinya kerusakan ekosistem pesisir secara masif sehingga menurunkan nilai pentingnya bagi ekosistem pesisir.

Kerusakan ekosistem mangrove secara signifikan mempengaruhi kondisi sumber daya perikanan baik terhadap kelimpahan maupun keragamannya (Bidayani et al. 2016b). Dampak yang ditimbulkan yaitu menurunnya tingkat pendapatan masyarakat khususnya nelayan secara signifikan. Jumlah dan jenis ikan hasil tangkapan secara signifikan mengalami penurunan akibat hilangnya daya dukung ekosistem bagi regenerasi dan perkembangan ikan.

Kerusakan ekosistem mangrove di wilayah pesisir juga berdampak terhadap pertambakan. Konversi hutan mangrove menjadi lahan tambak tanpa disadari telah menyebabkan terjadinya penurunan daya dukung lingkungan bagi pertambakan itu sendiri (Primavera 2006). Semakin tingginya intensitas kegiatan budidaya diiringi dengan semakin menipisnya hutan mangrove mengakibatkan limbah pertambakan tidak dapat terurai dengan baik bahkan terbawa ke laut dan menjadi pencemar bagi ekosistem laut. Perlahan, bahan pencemar yang terakumulasi menjadi gangguan bagi kultivan yang dibudidayakan dan semakin menurunkan 
produktivitas tambak. Pada akhirnya, pengelolaan tambak yang tidak mempertimbangkan keberlanjutan ekosistem justru mengakibatkan kerugian.

\section{HASIL DAN DISKUSI}

\section{Perkembangan Terapan Wanamina}

Perkembangan penerapan tambak wanamina di wilayah pesisir tidak lepas dari manfaat ekonomi yang lebih baik dibandingkan dengan tambak tradisional (Pardona et al. 2016). Tambak wanamina pertama kali diperkenalkan di Indonesia pada tahun 1978 oleh Departemen Kehutanan dengan tujuan untuk meminimalkan biaya penanaman mangrove, meningkatkan pendapatan pembudidaya dan mengkonservasi hutan mangrove (Takashima 2000). Proses pengenalan tersebut tentu saja tidak dapat secara langsung diterima oleh masyarakat, khususnya pembudidaya. Dibutuhkan waktu yang lama dan kontribusi yang bertahap dalam prosesnya, sehingga pembuktian di lapangan juga membutuhkan waktu yang lama hingga masyarakat mau menerima konsep yang ditawarkan (Primavera \& Esteban 2008). Diperlukan berbagai kesepakatan serta ketegasan terkait pemberian insentif dan denda terhadap pelaksanaan dan pelanggaran yang dilakukan. Sementara itu, penerapan tambak wanamina di kawasan Delta Mahakam dimulai sejak tahun 2001 (Santoso et al. 2007).

Upaya rehabilitasi mangrove, khususnya dalam tambak membutuhkan partisipasi masyarakat khususnya pemilik tambak agar dapat berjalan secara optimal. Tingkat kesadaran masyarakat yang tinggi akan pentingnya ekosistem mangrove bagi wilayah pesisir merupakan faktor dominan yang akan mempengaruhi keberhasilan pelestarian ekosistem mangrove (Madiama et al. 2016). Untuk itu, masyarakat perlu memahami berbagai manfaat hutan mangrove beserta keberlanjutan pemanfaatannya jika mangrove dilestarikan.

Kendala utama dalam penerapan tambak wanamina oleh masyarakat adalah tingkat kekhawatiran masyarakat akan menurunnya tingkat pendapatan yang diperoleh sebagai akibat dari penyusutan luas kolam (Baumgartner et al. 2016).

\section{Peningkatan Kualitas Lingkungan}

Ekosistem mangrove merupakan komponen penting dalam pengendalian kualitas lingkungan wilayah pesisir. Keberadaan ekosistem mangrove berperan dalam penyediaan jasa-jasa dan sumber daya lingkungan (Van et al. 2015). Mangrove berfungsi sebagai daerah perlindungan, mencari makan, pemijahan dan pembesaran berbagai jenis organisme air. Mangrove juga berperan dalam pengendalian siklus dan distribusi nutrien baik di dalam ekosistem mangrove sendiri maupun di lingkungan perairan sekitarnya. Mangrove juga dapat mengurangi distribusi bahan pencemar baik organik maupun anorganik. Sementara bagi wilayah daratan, mangrove berfungsi dalam pengendalian intrusi air laut serta memberikan perlindungan daratan pantai dari dinamika gelombang dan pasang surut yang menyebabkan terjadinya erosi. Hal inilah yang menjadikan mangrove sebagai ekosistem penting bagi wilayah pesisir.

Pemaduan mangrove dalam budidaya tambak melalui penerapan wanamina terbukti secara nyata mempengaruhi kualitas lingkungan dalam tambak. Hasil penelitian (Hastuti \& Budihastuti 2016a) menunjukkan bahwa tegakan mangrove secara signifikan mempengaruhi kandungan TSS, bahan organik, nitrogen, fosfor dan DO tambak. Hal ini menunjukkan bahwa mangrove memiliki peran yang nyata dalam meningkatkan kenyamanan lingkungan bagi kultivan serta menunjang kesuburan dan mencegah pencemaran nutrien dalam tambak.

Kehadiran vegetasi mangrove dalam tambak dapat meningkatkan kandungan $\mathrm{DO}$ dan $\mathrm{pH}$ sehingga menghindarkan resiko terjadinya hipoxia dan pengasaman, serta mampu menahan nutrien berupa nitrat dan fosfat yang merupakan unsur nutrien (Purwiyanto \& Agustriani 2014). Sementara penelitian (Hastuti 2017) menunjukkan bahwa struktur vegetasi mangrove berpengaruh terhadap tingkat serapan/akumulasi logam berat. 
Manfaat yang dihasilkan dari penerapan tambak wanamina adalah diperolehnya kondisi lingkungan yang relatif stabil (Suwarto et al. 2015). Dengan demikian, resiko terhadap gangguan akibat perubahan kondisi lingkungan tambak dapat dikurangan sehingga menunjang kelangsungan dan perkembangan kultivan secara optimal. Hal ini juga berarti bahwa tidak diperlukan adanya peralatan penunjang untuk menjaga kondisi lingkungan agar tetap optimal.

\section{Tipikal Produktivitas Tambak Wanamina}

Meskipun berbagai jenis kultivan dapat dibudidayakan dalam tambak wanamina, namun jenis kultivan yang umumnya dibudidayakan dalam tambak wanamina adalah ikan Bandeng. Hal ini dikarenakan tingkat resiko dan perawatan yang lebih mudah dibandingkan dengan budidaya udang (Pardona et al. 2016). Namun, dalam budidaya tambak wanamina pada umumnya juga dihasilkan hasil samping berupa kepiting maupun udang yang juga memiliki nilai ekonomis tinggi. Disamping itu juga terdapat jenis organisme lain yang dapat dimanfaatkan baik berupa ikan belanak, kerang, rumput laut serta manfaat lain dari beberapa jenis mangrove yang buahnya dapat diolah menjadi bahan makanan.

Tingkat produktivitas tambak wanamina pada umumnya berkaitan erat dengan perbandingan antara luas kolam dan luas mangrove. Semakin besar proporsi mangrove dibandingkan dengan tambak maka semakin rendah produksi kultivan budidaya yang dihasilkan, namun hasil samping yang dihasilkan justru semakin meningkat, demikian pula dengan daya dukungnya bagi produktivitas perikanan tangkap perairan disekitarnya (Sambu 2013). Hal ini menunjukkan bahwa besaran produktivitas tambak dapat dikendalikan berdasarkan proporsi antara luas mangrove dan luas kolam tambak yang diterapkan.

Berbagai jenis sumber daya dan jasa lingkungan disediakan oleh ekosistem mangrove. Namun, berbagai sumber daya yang disediakan oleh ekosistem mangrove tersebut pada umumnya hanya sebagian kecil saja yang bisa dimanfaatkan oleh manusia, yaitu pada bagian tepian saja
(Walters et al. 2008). Hal ini menyebabkan sumber daya yang ada di dalam ekosistem menjadi lebih terjaga dan mampu menunjang kelestariannya secara mandiri. Sehingga sumber daya yang ada dapat dimanfaatkan secara berkelanjutan tanpa perlu melakukan restoking atau penebaran sebagaimana kegiatan budidaya. Hal ini merupakan keuntungan sistem budidaya wanamina yang umumnya dianggap sebagai hasil samping. Meskipun dikategorikan sebagai hasil samping, namun pada umumnya biota-biota asosiasi mangrove merupakan komoditas sumber daya bernilai ekonomis tinggi seperti udang windu, kerapu, kepiting, kakap, kerang dan lain sebagainya.

\section{Sisi Negatif Wanamina}

Permasalahan yang sering dihadapi dalam penerapan tambak wanamina adalah proses pengelolaan yang relatif kompleks dibandingkan dengan tambak tradisional dan tambak intensif. Proses penanaman mangrove dalam tambak seringkali mengalami kegagalan akibat kondisi lingkungan yang kurang sesuai dengan habitat asli mangrove (Primavera \& Esteban 2008). Dibutuhkan waktu hingga bertahun-tahun untuk menghasilkan tegakan mangrove yang mantap serta adanya upaya penanaman ulang selama proses penghijauan yang dilakukan. Belum lagi perlunya kegiatan pemangkasan secara berkala untuk mencegah mangrove yang terlalu rimbun yang justru berpotensi menurunkan produktivitas tambak. Hal ini jika tidak dilakukan upaya pemanfaatan yang terpadu yang mengarah pada produktivitas secara ekonomi maka berpotensi menurunkan minat masyarakat untuk menerapkan sistem wanamina dalam budidaya tambak.

Menerapkan sistem budidaya wanamina berarti menerapkan kegiatan budidaya dalam kondisi habitat alaminya. Hal ini berarti bahwa jenis-jenis kultivan yang ditanam adalah jenis-jenis kultivan tertentu yang memang berasosiasi atau hanya dapat tumbuh optimal di dalam ekosistem mangrove saja. Pemilihan jenis kultivan yang kurang sesuai dengan daya dukung lingkungan yang ada mengakibatkan tingkat produktivitas yang relatif rendah (Budihastuti et al. 2012). 
Dalam budidaya dengan tambak wanamina maka produktivitas tidak dapat ditumpukan pada jenis kultivan yang dibudidayakan saja. Terlebih jika proporsi lahan untuk mangrove lebih besar dibandingkan dengan kolam, maka hasil samping budidaya merupakan komoditas yang perlu dipertimbangkan produktivitasnya (Sambu 2013). Perencanaan desain sejak awal pembuatan tambak wanamina perlu mempertimbangkan faktor-faktor tersebut sehingga diperoleh produktivitas yang diharapkan baik terhadap jenis kultivan yang dibudidayakan maupun hasil sampingnya.

Tidak jarang, jenis-jenis biota hasil samping terkadang justru memiliki nilai ekonomi yang lebih baik dibandingkan dengan komoditas utama budidaya. Kepiting misalnya, permintaan pasar cenderung mengalami peningkatan padahal secara praktis pembenihan dan budidaya kepiting masih relatif rendah (Mirera 2011). Sehingga, produksi kepiting untuk konsumsi didominasi dari hasil penangkapan kepiting liar. Tambak wanamina merupakan tehnik budidaya yang tepat untuk meningkatkan produktivitas hewan liar seperti kepiting bakau tersebut.

\section{Peningkatan Tata Kelola}

Pola pengelolaan ekosistem mangrove yang saat ini diterapkan di Indonesia meliputi beberapa rezim, antara lain berupa hutan mangrove alami untuk konservasi dan perlindungan, pemanfaatan hutan mangrove dengan intensitas rendah hingga tinggi untuk tujuan produksi dan rehabilitasi, konversi sebagai lahan budidaya terintegrasi dan konversi total sebagai lahan tambak (Van Oudenhoven et al. 2014).

Pemaduan kegiatan budidaya dengan kegiatan konservasi mangrove membutuhkan perencanaan yang matang untuk mendapatkan hasil yang diharapkan. Komposisi alokasi lahan untuk mangrove dan kolam perlu diperhatikan. Semakin besar proporsi lahan untuk mangrove akan menghasilkan lebih banyak hasil samping dan manfaat ekologis bagi perairan di sekitarnya, namun produktivitas kultivan yang dibudidayakan justru semakin rendah. Sebaliknya, jika proporsi lahan untuk kolam tambak lebih besar maka fungsi ekologisnya semakin rendah (Sambu 2014).
Upaya peningkatan produktivitas tambak wanamina semakin dikembangkan dari waktu ke waktu. Tata kelola merupakan prinsip penting dalam upaya peningkatan produktivitas tersebut, antara lain dengan upaya diversifikasi kultivan budidaya dan peningkatan daya dukung lingkungan (Suwarto et al. 2015). Hal tersebut diantaranya dapat diupayakan dengan pemilihan jenis dan ukuran vegetasi serta struktur penanaman yang tepat.

Penggunaan vegetasi mangrove dalam tambak wanamina perlu memperhatikan aspek lingkungan yang ada. Pada kawasan pesisir yang telah mengalami kerusakan maka daya dukung lahan pun semakin berkurang. Penelitian (Hastuti \& Hastuti 2016) menunjukkan bahwa suhu perairan secara signifikan mempnegaruhi tingkat kelulushidupan semai A. marina yang ditanam di wilayah pesisir Kota Semarang, namun tidak terhadap kelulushidupan semai $R$. mucronata. Penelitian yang dilaksanakan selama kurun waktu 1 tahun dengan periode observasi selama 3 bulan diperoleh tingkat kelulushidupan semai A. marina paling rendah sebesar $5,56 \%$ dan paling tinggi sebesar $14,81 \%$, sedangkan pada semai $R$. mucronata tingkat kelulushidupan paling rendah mencapai 22,22\% dan paling tinggi sebesar $38,89 \%$. Hal ini menunjukkan bahwa kondisi lingkungan awal secara signifikan mempengaruhi kesesuaian jenis mangrove yang dapat ditanam dalam tambak.

Upaya peningkatan tata kelola tambak wanamina telah dilakukan diantaranya oleh (Wibowo \& Handayani 2006) dengan modifikasi model empang parit. Pada umumnya tambak wanamina dengan model empang parit membagi antara kolam budidaya dengan mangrove dimana mangrove ditanam mengelilingi kolam atau di tengah kolam. Modifikasi dilakukan dengan membagi kolam menjadi dua yaitu di dalam dengan dikelilingi mangrove dan di luar mangrove dengan harapan dapat meningkatkan produktivitasnya. Sementara (Hastuti 2017)

Penggunaan jenis kultivan yang sesuai merupakan salah satu upaya yang dapat dilakukan untuk menghasilkan produktivitas budidaya yang optimal dalam tambak wanamina. Penelitian (Budihastuti et al. 2012) menunjukan bahwa jenis 
vegetasi berpengaruh terhadap produktivitas kultivan yang dibudidayaan. Hasil penelitian tersebut menunjukkan bahwa tambak wanamina dengan tegakan R. mucronata lebih optimal bagi budidaya ikan Bandeng (Chanos chanos) sedangkan A. marina lebih optimal bagi budidaya ikan Nila (Oreochromis niloticus).

Upaya lain yang dilakukan untuk meningkatkan produktivitas tambak wanamina yaitu dengan memadukan kegiatan budidaya dengan kegiatan pertanian dan peternakan (Ogello et al. 2013). Pengelolaan terpadu tersebut terbukti dapat meningkatkan produktivitas tambak disamping mengurangi dampak pencemaran dari kegiatan peternakan. Biaya operasional dalam kegiatan budidaya juga dapat dikurangi sehingga menghasilkan tingkat pendapatan yang lebih tinggi. Hasil budidaya pun relatif lebih baik karena usaha budidaya cenderung bersifat organik.

\section{Peran Vegetasi Mangrove}

Penerapan tambak wanamina pada awal pengenalannya ditunjukan untuk mengatasi permasalahan pencemaran yang ditimbulkan dari kegiatan budidaya intensif (Anh et al. 2010). Namun seiring dengan perkembangan penelitian mengenai peran vegetasi mangrove pemanfaatan mangrove dalam tambak wanamina semakin berkembang, mulai dari sebagai penyedia nutrien dan pakan alami hingga sebagai penghasil hasil tangkap / budidaya sampingan. Dengan demikian, vegetasi mangrove dapat dikatakan memiliki fungsi beragam dalam tambak wanamina.

Penanaman mangrove pada lahan pertambakan, pada umumnya mengacu pada ketertarikan masyarakat pada jenis mangrove tertentu. Hal ini berdampak pada terjadinya dominasi jenis-jenis tanaman tertentu di kawasan pesisir yang dikehendaki oleh masyarakat (Van et al. 2015). Disamping itu, perubahan kondisi lingkungan akibat degradasi lahan juga berdampak pada kesesuaian jenis-jenis mangrove yang dapat ditanam dalam lingkungan tambak. Dilihat dari kondisi lingkungan yang cenderung tergenang serta dominannya pengaruh pasang surut dalam tambak, maka jenis-jenis mangrove yang umumnya dapat ditanam merupakan jenis-jenis mangrove perintis. Jenis-jenis mangrove yang umumnya ditemui di lingkungan pertambakan antara lain adalah Avicennia marina, Rhizophora mucronata, Rhizophora apiculata, dan Bruguiera gymnorrhiza.

Jasa-jasa lingkungan ekosistem sangat beragam, namun yang menjadi perhatian serius terkait kegiatan budidaya tambak adalah kemampuannya menetralisir limbah tambak (Walters et al. 2008). Kemampuan tersebut diantaranya berupa penyerapan fosfat, nitrat dan karbon serta pemerangkapan sedimen. Mangrove memiliki peran dalam menyerap dan mendistribusikan kembali berbagai jenis nutrien yang masuk ke dalam ekosistem melalui guguran serasah sehingga nutrien dapat tersimpan dalam waktu yang lama dan dapat terdistribusi secara terkendali.

Vegetasi mangrove yang ditanam dalam lingkungan tambak memberikan pengaruh yang berbeda berdasarkan jenis dan populasinya. Bahkan tinggi dan diameter tegakan terbukti masing-masing dapat memberikan pengaruh yang berbeda terhadap kualitas air dibawahnya (Hastuti \& Budihastuti 2016a). Hasil penelitian tersebut menunjukkan bahwa pada struktur mangrove dengan kombinasi antara Avicennia marina dan Rhizophora mucronata, populasi A. marina secara signifikan berpengaruh terhadap penurunan kekeruhan sedangkan populasi R. mucronata justru meningkatkan kekeruhan air. Sementara konsentrasi DO secara signifikan dipengaruhi oleh tinggi A. marina dan R. mucronata secara negatif dan diameter A. marina positif. Tinggi tegakan R. mucronata secara parsial berpengaruh terhadap penurunan TSS, peningkatan kadar bahan organik, $\mathrm{N}$ dan $\mathrm{P}$.

Selain terhadap kualitas lingkungan secara fisik dan kimia, mangrove juga memiliki peranan penting terhadap pengendalian sumber daya biologi yang ada di sekitarnya. Jenis vegetasi berpengaruh terhadap komposisi jenis bentos yang ada di dasar tambak. Hal ini dibuktikan oleh (Budihastuti 2015) yang menunjukkan bahwa bentos pada tambak wanamina dengan jenis mangrove Rhizophora mucronata memiliki jumlah spesies dan keragaman yang lebih tinggi dibandingkan dengan tambak wanamina dengan 
mangrove Avicennia marina. Padahal, beberapa jenis bentos merupakan sumber daya perikanan yang memiliki nilai ekonomis sehingga dapat dimanfaatkan.

Fungsi lebih jauh dari vegetasi mangrove adalah sebagai sumber pakan alami bagi kultivan. Penelitian (Gatune et al. 2014) membuktikan bahwa kandungan bioenergetik udang windu terdapat asam lemak ARA, EPA dan DHA yang konsentrasinya berkaitan dengan sejumlah serasah mangrove yang telah terdekomposisi dalam waktu tertentu. Hal ini menunjukan bahwa jenis mangrove memiliki peranan yang cukup penting bagi daya dukung yang dihasilkan bagi jenis kultivan yang akan dibudidayakan. Walaupun proses penyediaan makanan oleh mantgrove bagi organisme air secara umum bukan hanya terdapat pada faktor dekomposisinya saja, tetapi justru didasarkan pada kompleksitas rantai makanan yang dihasilkan.

\section{Implikasi Praktis}

Dampak praktis dari penerapan wanamina dalam kegiatan budidaya tambak adalah meningkatnya daya dukung ekosistem terhadap ketersediaan pakan alami bagi kultivan. Penelitian yang dilakukan oleh (Budihastuti et al. 2013) menunjukkan adanya kemiripan komposisi plankton dalam tambak wanamina dengan isi perut ikan Nila yang dibudidayakan didalamnya. Jenis dan komposisi plankton yang ditemukan dalam tambak wanamina cenderung bervariasi berdasarkan jenis mangrove yang ditanam di dalamnya. Hal ini mengindikasikan bahwa jenis mangrove secara signifikan mempengaruhi kesuburan tambak yang mempengaruhi kelimpahan pakan alami bagi kultivan dan pada akhirnya akan mempengaruhi produktivitasnya.

Dampak praktis budidaya tambak dengan sistem wanamina meliputi berbagai aspek baik terhadap ekologi maupun produksi. Dampak ekologis yang ditimbulkan dalam tambak wanamina yaitu adanya variasi kandungan bahan organik (Hastuti \& Budihastuti 2016b). Variasi tersebut mengindikasikan potensi ketersediaan nutrien dalam tambak wanamina yang menentukan tingkat kesuburan tambak.
Organisme bentos merupakan salah satu komponen penting yang mengindikasikan kondisi kualitas sedimen perairan merupakan komponen penting lain yang secara nyata terdampak oleh penerapan wanamina (Budihastuti 2015). Bahkan, sebagian jenis organisme bentos merupakan bagian dari sumber daya perikanan yang dapat dimanfaatkan dan memiliki nilai ekonomis. Maka dari itu, pemanfaatan sumber daya pada tambak wanamina tentu tidak hanya difokuskan pada jenis kultivan yang dibudidayakan saja. (Sambu 2013) menjelaskan bahwa ekosistem mangrove juga memberikan kontribusi terhadap ketersediaan berbagai jenis sumber daya ikan mulai dari udang windu, ikan bandeng, rumput laut, udang liar, ikan liar, kepiting, kerang-kerangan, nener dan benur yang semuanya dapat dimanfaatkan oleh masyarakat sekitar.

Implikasi praktis pengelolaan wanamina di lingkungan pesisir tentu tidak hanya mengandalkan sektor produksi perikanan budidaya saja. Berbagai aktivitas tambahan perlu dikembangkan untuk menunjuang kegiatan konservasi seiring dengan upaya peningkatan taraf ekonomis masyarakat pesisir, khususnya pembudidaya. Beberapa kegiatan yang umumnya dikembangkan di kawasan tambak wanamina antara lain budidaya ikan, penangkapan, produksi kayu mangrove secara komersial, serta pengembangan ekowisata kawasan tambak (Yuniarti et al. 2016).

Perubahan nilai ekonomis mangrove merupakan salah satu ancaman bagi keberlanjutan pelestarian mangrove di lingkungan pesisir. Seiring dengan bertambahnya usia mangrove, maka semakin tinggi pula potensi ekonominya dan peluang pemanfaatannya. Hal ini berpotensi mempengaruhi pola pikir masyarakat lokal dalam memanfaatkan kayu mangrove (Furukawa et al. 2015). Masyarakat yang semula hanya memanfaatkan jasa-jasa lingkungan mangrove dalam penyediaan sumber daya ikan mungkin akan beralih pada pemanfaatan kayu mangrove. Hal ini mengancam keberlanjutan konservasi mangrove yang telah dilakukan. Karenannya, perlu adanya upaya peningkatan pemahaman masyarakat secara konsisten dalam pelestarian eksosistem mangrove. 
Rehabilitasi dan pelestarian hutan mangrove membutuhkan partisipasi aktif dari masyarakat. Rendahnya partisipasi masyarakat mengakibatkan upaya rehabilitasi berjalan lambat (Rusdianti \& Sunito 2012). Faktor ekonomi merupakan salah satu kendala yang perlu diatasi dalam upaya tersebut. Pemahaman masyarakat mengenai manfaat hutan mangrove secara ekonomi perlu ditingkatkan dengan bukti-bukti nyata baik dari kegiatan budidaya maupun kegiatan penangkapan, sehingga masyarakat menyadari bahwa pelestarian mangrove merupakan upaya untuk membuka peluang usaha dan peningkatan kesejahteraan.

Diantara berbagai manfaat yang disediakan oleh ekosistem mangrove, manfaat tidak langsung merupakan manfaat yang secara ekonomi memiliki nilai paling besar dibandingkan dengan manfaat yang lain. Manfaat tidak langsung tersebut diantaranya meliputi fungsi perlindungan pantai, fungsi penyediaan pakan alami dan fungsi ekowisata (Indrayanti et al. 2015). Hal ini menunjukkan potensi ekonomi yang luar biasa besar jika pemaduan kegiatan budidaya dengan rehabilitasi mangrove dapat berjalan secara optimal.

Penerapan wanamina dalam pengelolaan wilayah pesisir berfungsi untuk menengahi kepentingan konservasi dan budidaya tambak. Terjaganya kelestarian hutan mangrove maka secara tidak langsung beban pemerintah dalam mengatasi berbagai masalah kerusakan pesisir dapat dikurangi. Manfaat lain yang dihasilkan yaitu terciptanya lapangan kerja dan peningkatan kesejahteraan masyarakat pesisir, khususnya nelayan oleh peningkatan sumber daya hayati wilayah pesisir. Masyarakat pembudidaya juga terjamin keberlanjutan usaha budidaya yang dilakukan karena ancaman terhadap degradasi lingkungan tambak dapat dikurangi. Pada akhirnya, budidaya tambak dengan sistem wanamina diharapkan dapat memberikan kontribusi bagi pembangunan wilayah dan peningkatan kesejahteraan masyarakat, baik secara ekologis, sosial, ekonomi dan budaya.

\section{DAFTAR PUSTAKA}

Amrial, Y., Effendi, H. \& Damar, A., 2015.
Pengelolaan Ekosistem Mangrove Berbasis Silvofishery di Kecamatan Cibuaya, Kabupaten Karawang. Jurnal Kebijakan Sosek Kelautan Perikanan, 5(1), pp.59-70.

Anh, P.T. et al., 2010. Water Pollution by Intensive Brackish Shrimp Farming in South-East Vietnam: Causes and Options for Control. Agricultural Water Management, 97(6), pp.872-882. Available at:http://dx.doi.org/10.1016/j.agwat.2010.01 .018 .

Baumgartner, U., Kell, S. \& Nguyen, T.H., 2016. Arbitrary Mangrove-to-Water Ratios Imposed on Shrimp Farmers in Vietnam Contradict with the Aims of Sustainable Forest Management. SpringerPlus, 5, p.438.

Bidayani, E. et al., 2016a. Blue Economy Approach-Based Mangrove Resources Conservation for Coastal Community's Prosperity in Sidoarjo Regency, East Java, Indonesia. International Journal of Ecosystem, 6(1), pp.1-9.

Bidayani, E. et al., 2016b. Implementation of Blue Economy Concept as the Efforts of Mangrove Resource Conservation in Sidoarjo Coastal Area, East Java, Indonesia. International Journal of Ecosystem, 6(2), pp.25-34.

Budihastuti, R., 2015. Variasi Periodik Komposisi Bentos pada Tambak Wanamina dengan Jenis Mangrove Berbeda. Jurnal Litbang Provinsi Jawa Tengah, 13(2), pp.135-142.

Budihastuti, R., Anggoro, S. \& Saputra, S.W., 2013. Analysis on the Feeding Habit of Tilapia (Oreochromis niloticus) Cultured in Silvofishery Pond in Semarang. Journal of Environment and Ecology, 4(2), pp.1-6.

Budihastuti, R., Anggoro, S. \& Saputra, S.W., 2012. The Application of Silvofishery on Tilapia (Oreochromis niloticus) and Milkfish (Chanos chanos) Fattening within Mangrove Ecosystem of the Northern Coastal Area of Semarang City. Journal of Coastal Development, 16(1), pp.89-93.

Bush, S.R. et al., 2010. Scenarios for Resilient Shrimp Aquaculture in Tropical Coastal 
Areas. Ecology and Society, 15(2), p.15.

Dolorosa, E. et al., 2014. Analisis Kelayakan FinansialUsaha Perikanan Tambak Polikultur Bandeng-Udang Windu. Jurnal Social Economic of Agriculture, 3(2), pp.20-36.

Furukawa, F., Kobayashi, S. \& Iwata, A., 2015. Changing Relationships Between Mangrove Resources and Local Residents in South Sulawesi and Maluku, Indonesia. TROPICS, 24(1), pp.33-46.

Gatune, W.C. et al., 2014. Fatty Acid Profiling Reveals A Trophic Link Between Mangrove Leaf Litter Biofilms and the Post-Larvae of Giant Tiger Shrimp Penaeus monodon. Aquaculture Environment Interactions, 6, pp.1-10.

Haris, A. et al., 2013. Correlation between Mangrove and Aquaculture Production: Case Study in Sinjai District, Sulawesi. International Journal of Aquaculture, 3(14), pp.73-78.

Hastuti, E.D., 2017. Penerapan Wanamina: Kelulushidupan Semai Mangrove, Variasi Kualitas Lingkungan dan Perubahan Kandungan Logam Berat. Buletin Anatomi dan Fisiologi, 2(1), pp.17-25.

Hastuti, E.D. \& Budihastuti, R., 2016a. Potential of Mangrove Seedlings for Utilization in the Maintenance of Environmental Quality within Silvofishery Ponds. Biotropia, 23(1), pp.58-63.

Hastuti, E.D. \& Budihastuti, R., 2016b. Variasi Kandungan Nutrien dalam Tambak Wanamina dengan Komposisi Jenis dan Jumlah Tegakan Mangrove yang Berbeda di Pesisir Kota Semarang. Buletin Anatomi dan Fisiologi, 1(1), pp.36-42.

Hastuti, E.D. \& Hastuti, R.B., 2016. Analisis Hubungan Suhu Air dengan Mortalitas Semai Mangrove pada Tambak Wanamina. In Seminar Nasional from Basic Science to Comprehensive Education. Makassar: Jurusan Biologi, Fakultas Sains dan Teknologi, UIN Alauddin, pp. 11-15.

Indrayanti, M.D., Fahrudin, A. \& Setiobudiandi, I., 2015. Penilaian Jasa Ekosistem Mangrove di
Teluk Blanakan Kabupaten Subang. Jurnal Ilmu Pertanian Indonesia, 20(2), pp.91-96.

Madiama, S., Muryani, C. \& Santoso, S., 2016. Kajian Perubahan Luas dan Pemanfaatan Serta Persepsi Masyarakat terhadap Pelestarian Hutan Mangrove di Kecamatan Teluk Ambon Baguala. Jurnal GeoEco, 2(2), pp.170-183.

Mirera, O.D., 2011. Trends in Exploitation, Development and Management of Artisanal Mud Crab (Scylla serrata-Forsskal-1775) Fishery and Small-Scale Culture in Kenya: An overview. Ocean and Coastal Management, 54(11), pp.844-855. Available at: http://dx.doi.org/10.1016/j.ocecoaman.2011. 08.001 .

Ogello, E.O. et al., 2013. Can Integrated Livestock-Fish Culture Be A Solution to East Africa's Food Insecurity? A Review. African Journal of Food, Agriculture, Nutrition and Development, 13(4), pp.80588076.

Van Oudenhoven, A.P.E. et al., 2014. Effects of Different Management Regimes on Mangrove Ecosystem Services in Java, Indonesia, Wageningen, Ede \& Bogor: Wageningen University (Wageningen) \& Wetlands International (Ede \& Bogor).

Pardona, P., Agustriani, F. \& Sarno, 2016. Analisis Finansial Usaha Budidaya Tambak Sistem Tradisional dan Silvofishery di Area Restorasi Taman Nasional Sembilang Sumatera Selatan. Maspari Journal, 8(1), pp.1-6.

Paruntu, C.P., Windarto, A.B. \& Mamesah, M., 2016. Mangrove dan Pengembangan Silvofishery di Wilayah Pesisir Desa Arakan Kecamatan Tatapaan Kabupaten Minahasa Selatan sebagai Iptek Bagi Masyarakat. Jurnal LPPM Bidang Sains dan Teknologi, 3(2), pp.1-25.

Primavera, J.H., 2006. Overcoming the Impacts of Aquaculture on the Coastal Zone. Ocean \& Coastal Management, 49, pp.531-545.

Primavera, J.H. \& Esteban, J.M.A., 2008. A Review of Mangrove Rehabilitation in the 
Philippines: Successes, Failures and Future Prospects. Wetlands Ecology and Management, 16(5), pp.345-358.

Purwiyanto, A.I.S. \& Agustriani, F., 2014. Effect of Silvofishery on Ponds Nutrient Levels. Ilmu Kelautan, 19(2), pp.81-87.

Rusdianti, K. \& Sunito, S., 2012. Konversi Lahan Hutan Mangrove serta Upaya Penduduk Lokal dalam Merehabilitasi Ekosistem Mangrove. Sodality: Jurnal Sosiologi Pedesaan, 6(1), pp.1-17.

Sambu, A.H., 2014. Analysis of Characteristics of and Use Value of Mangrove Ecosystem ( Case Study in Samataring and Tongketongke Sub-Districts , Sinjai Regency )., 5(2), pp.222-233.

Sambu, A.H. et al., 2013. Desain Tambak Silvofishery Ramah Lingkungan Berbasis Daya Dukung: Studi Kasus Kelurahan Samataring, Kabupaten Sinjai. Jurnal Segara, 9(2), pp.157-165.

Sambu, A.H., 2013. Korelasi Mangrove dengan Produksi Perikanan Budidaya (Studi Kasus Kabupaten Sinjai). Octopus, 2(1), pp.151158.

Santoso, E., Djuhriansyah \& Gunawan, B.I., 2007. Analisis Kebijakan Pembangunan Pertambakan di Kawasan Delta Mahakam Kabupaten Kutai Kertanegara. Jurnal Kehutanan UNMUL, 3(2), pp.115-129.

Suwarto et al., 2015. Ecological Aspect of Non Productive Fishponds at Mahakam Delta Area: Revitalization with Silvofishery System. Global Journal of Agricultural Research, 3(1), pp.27-35.

Takashima, F., 2000. Silvofishery: An Aquaculture System Harmonized with the Environment. In J. H. Primavera et al., eds. MangroveFriendly Aquaculture: Proceedings of the Workshop on Mangrove-Friendly Aquaculture organized by the SEAFDEC Aquaculture Department. Tigbauan, Iloilo, Philippines: Southeast Asian Fisheries Development Center, Aquaculture Department, pp. 13-19.

Van, T.T. et al., 2015. Changes in Mangrove
Vegetation Area and Character in a War and Land Use Change Affected Region of Vietnam (Mui Ca Mau) Over Six Decades. Acta Oecologica, 63, pp.71-81. Available at:http://dx.doi.org/10.1016/j.actao.2014.11. 007.

Walters, B.B. et al., 2008. Ethnobiology, SocioEconomics and Management of Mangrove Forests: A Review. Aquatic Botany, 89, pp.220-236.

Wibowo, K. \& Handayani, T., 2006. Pelestarian Hutan Mangrove Melalui Pendekatan Mina Hutan (Silvofishery). Jurnal Teknik Lingkungan, 7(3), pp.227-233.

Yuniarti, I. et al., 2016. Mangrove of Berau: Ecological Condition, Fisheries, and Management Options. Indonesian Fisheries Research Journal, 22(1), pp.37-42. 